\title{
Reversible Electrochemical Tuning of Ion Sieving in Coordination
}

\section{Polymers}

Zhong-Qiu Li ${ }^{\ddagger}$, Ming-Yang $\mathrm{Wu}^{\star}$, Xin-Lei Ding, Zeng-Qiang Wu, Xing-Hua Xia*

State Key Laboratory of Analytical Chemistry for Life Science, School of Chemistry and Chemical Engineering, Nanjing University, Nanjing 210023, China

$\$$ These authors contributed equally.

*Correspondence: xhxia@nju.edu.cn

\section{Table of Contents}

S1. Fabrication process of ETISM

S2. Relationship between ionic conductivity and concentration of $\mathrm{KCl}$ solution

S3. SEM images of AAO and AAO sputtered with gold

S4. X-ray diffraction (XRD) patterns of ETISM

S5. Demonstration of the membrane integrity with dye diffusion

S6. Raman spectra of ETISM

S7. Electrochemical conversion between PB and PW

S8. Lifetime of PW membrane with and without nitrogen gas purging

S9. SEM images of PB membrane fabricated via different deposition time

S10. Permeation rate of $\mathrm{K}^{+}$across ETISM with different deposition times 


\section{S1. Fabrication process of ETISM}

ETISM was fabricated by a chemical solution deposition method. A gold film was previously sputtered on an anodic aluminum oxide (AAO) substrate, followed by deposition of Prussian blue (PB) film (Figure S1).

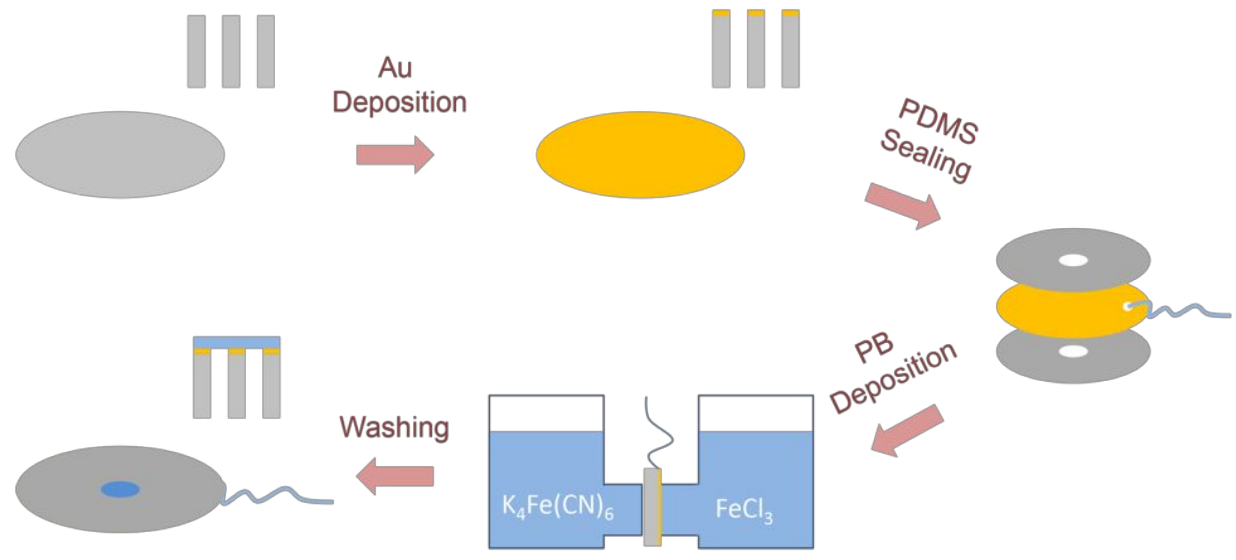

Figure S1. Fabrication process of ETISM. 


\section{S2. Relationship between ionic conductivity and concentration of $\mathrm{KCl}$ solution}

For a strong electrolyte, the difference between the limiting molar ionic conductivity and the actual molar ionic conductivity becomes smaller with decreasing the ionic concentration. Through comparing the molar ionic conductivity of the cations used in this study at $0.001 \mathrm{~mol} / \mathrm{L}$ with their limiting molar ionic conductivity, we found that the deviation was below $8 \%$ for all these cations (Table S1). It is reasonable to take limiting molar ionic conductivity as the actual molar ionic conductivity because the ionic concentration at permeate side was always below $0.001 \mathrm{~mol} / \mathrm{L}$. Therefore, the ionic concentration can be calculated as $\mathrm{c}=\kappa / \Lambda_{\mathrm{m}, \infty}$. This relationship was confirmed by measuring the ionic conductivity of $\mathrm{KCl}$ solutions of known concentrations. (Figure S2)

Table S1. Comparison of limiting molar ionic conductivity and molar ionic conductivity at $0.001 \mathrm{~mol} / \mathrm{L}$ for different cations.

\begin{tabular}{|c|c|c|c|}
\hline & $\begin{array}{c}\text { Limiting Molar Ionic } \\
\text { Conductivity } \\
\left(\Lambda_{\mathrm{m}, \infty}, 10^{-4} \mathrm{~m}^{2} \mathrm{~S} \mathrm{~mol}^{-1}\right)\end{array}$ & $\begin{array}{c}\text { Molar Ionic Conductivity } \\
(0.001 \mathrm{~mol} / \mathrm{L}) \\
\left(\Lambda_{\mathrm{m}}, 10^{-4} \mathrm{~m}^{2} \mathrm{~S} \mathrm{~mol}^{-1}\right)\end{array}$ & Deviation \\
\hline $\mathrm{CsCl}$ & 133.5 & 130.7 & $2.1 \%$ \\
\hline $\mathrm{KCl}$ & 130 & 127.3 & $2.1 \%$ \\
\hline $\mathrm{NaCl}$ & 109 & 106.5 & $2.3 \%$ \\
\hline $\mathrm{LiCl}$ & 98.9 & 96.5 & $2.4 \%$ \\
\hline $\mathrm{MgCl}_{2}$ & 221.8 & 212 & $4.4 \%$ \\
\hline $\mathrm{LaCl}_{3}$ & $298.53\left(25^{\circ} \mathrm{C}\right)$ & $274\left(25{ }^{\circ} \mathrm{C}\right)$ & $8.0 \%$ \\
\hline
\end{tabular}




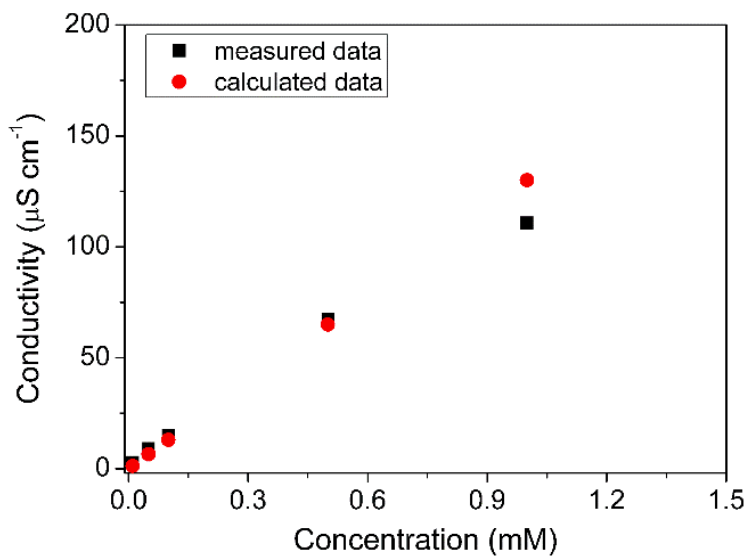

Figure S2. Relationship between ionic conductivity and concentration of $\mathrm{KCl}$ solutions. 


\section{S3. SEM images of AAO and AAO sputtered with gold}

Both AAO and AAO sputtered with gold show through-hole structures (Figure S3). After sputtering with gold, a gold layer can be seen on the top of the membrane.
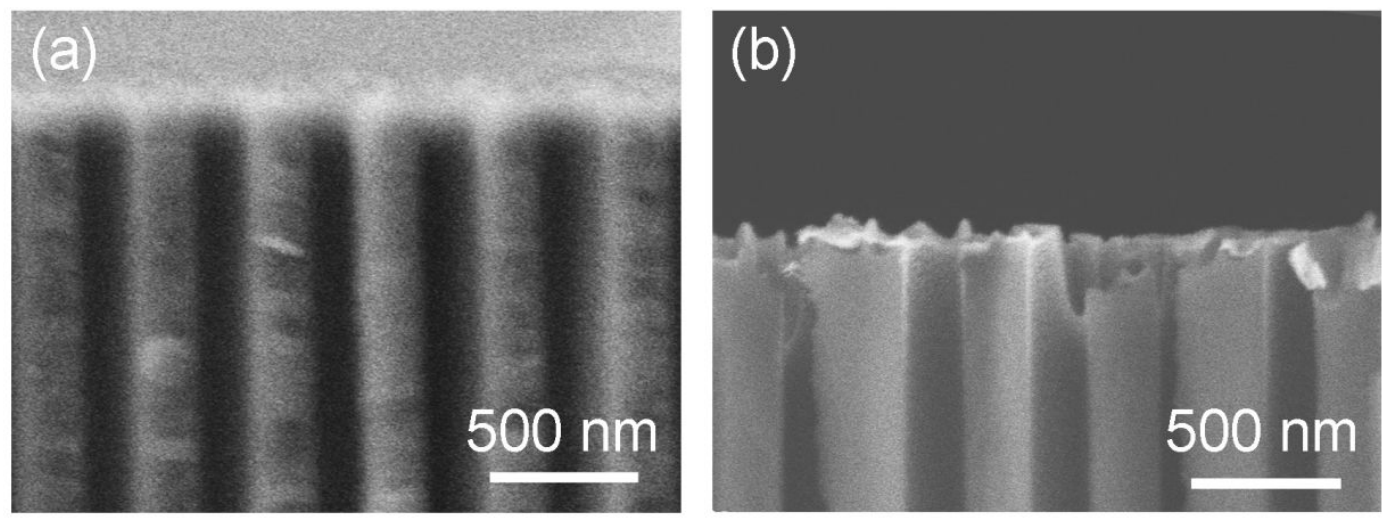

Figure S3. Cross-section SEM images of AAO (a) and AAO sputtered with gold (b). 


\section{S4. X-ray diffraction (XRD) patterns of ETISM}

As shown in Figure S4, the XRD pattern of ETISM matches well with the ones of PB powder and the simulations, indicating a well-organized structure. The peaks at $28^{\circ}$ and $41^{\circ}$ correspond to the diffraction of $\mathrm{KCl}$ adsorbed on the surface of the membrane.

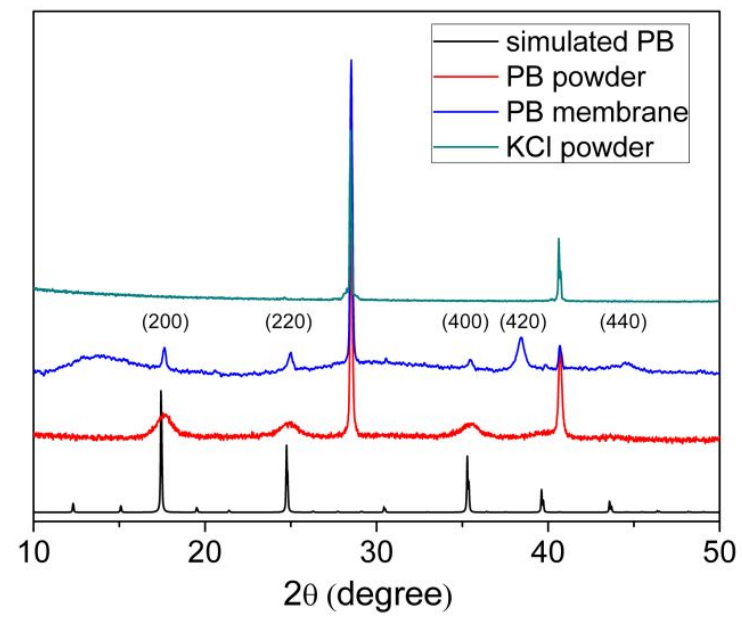

Figure S4. XRD patterns of the simulated $\mathrm{PB}, \mathrm{PB}$ powder, $\mathrm{PB}$ membrane and $\mathrm{KCl}$ powder. 


\section{S5. Demonstration of the membrane integrity with dye diffusion}

Resorufin (a dye molecule with a hydrated radius of $0.26 \mathrm{~nm}$ ) solution and pure water were separately added in the half cells at two sides of the ETISM. The concentration of resorufin at the pure water side was monitored by the absorbance at the wavelength of $570 \mathrm{~nm}$ using an UV-visible spectrophotometer. As revealed by Figure S5, the resorufin diffuses fast through a bare membrane, while resorufin can be hardly detected at the permeate side after a 1-h diffusion, indicating a no-crack structure.

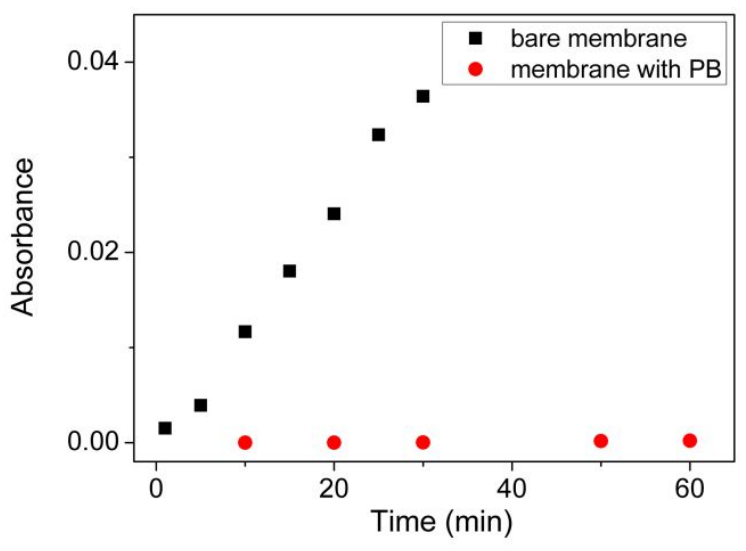

Figure S5. UV-vis absorption of resorufin at the permeate side of ETISM versus time. Resorufin concentration at the feed side was $100 \mu \mathrm{M}$ and pure water was initially added at the permeate side. 


\section{S6. Raman spectra of ETISM}

The Raman spectra of ETISM show a good reversibility during electrochemical switches of the membrane state between PB and PW (Prussian white) (Figure S6), indicating a reversible conversion process.

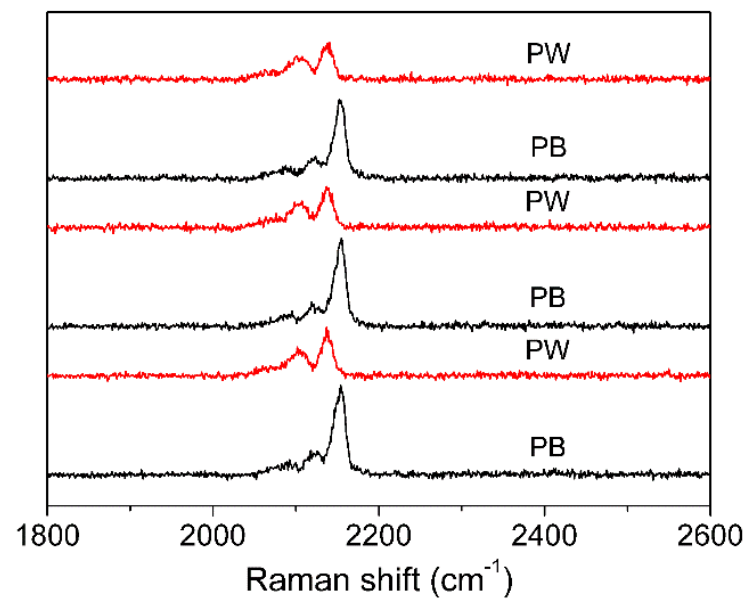

Figure S6. Raman spectra of ETISM upon electrochemical switches of the membrane states. 


\section{S7. Electrochemical conversion between PB and PW}

As shown in Figure S7, electrochemical conversion between PB and PW can be completed in $200 \mathrm{~s}$. Therefore, we chose $200 \mathrm{~s}$ as the time to apply the reduction and oxidation voltages.

(a)

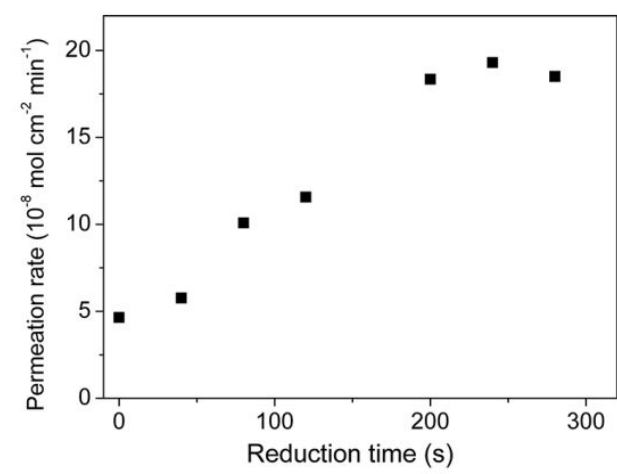

(b)

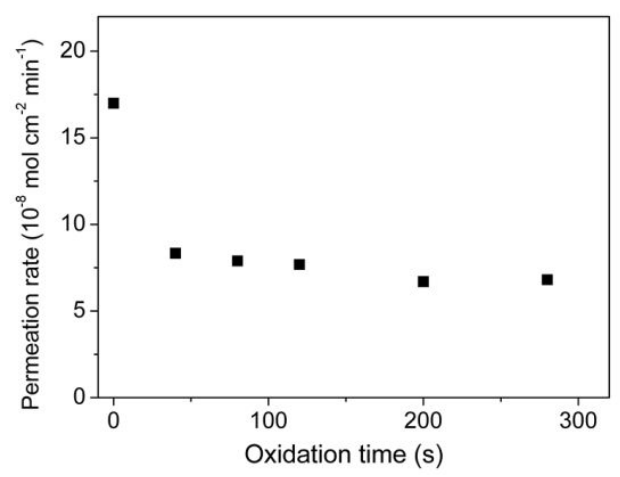

Figure S7. Permeation rates of $\mathrm{K}^{+}$versus reduction (a, - $\left.0.2 \mathrm{~V}\right)$ and oxidation (b, 0.6 V) times. 


\section{S8. Lifetime of PW membrane with and without nitrogen gas purging}

After converting the membrane state into $\mathrm{PW}$, the $\mathrm{K}^{+}$permeation rate across the membrane was monitored. As shown in Figure S8, the PW membrane can maintain its permeability for more than $1 \mathrm{~h}$ with nitrogen gas purging. However, if nitrogen gas was not introduced, the permeability of PW membrane would quickly decrease to a lower value in 10 min because PW can be easily oxidized into PB by the dissolved oxygen.

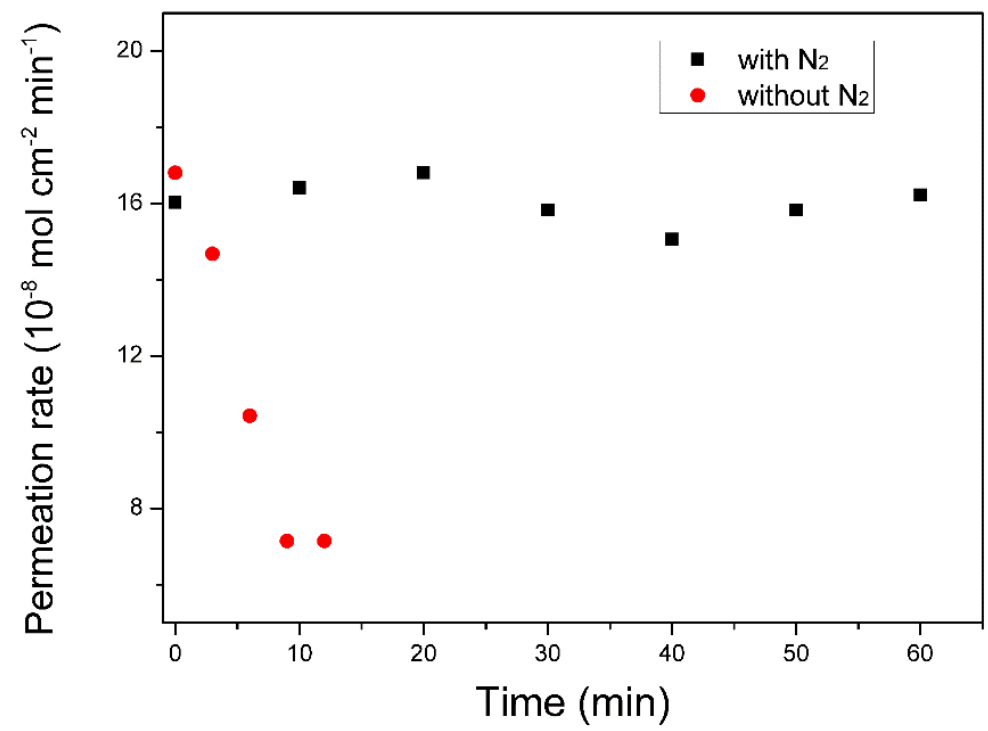

Figure S8. Permeation rates of $\mathrm{K}^{+}$across $\mathrm{PW}$ membrane with and without purging nitrogen gas. 


\section{S9. SEM images of PB membrane fabricated via different deposition time}

As shown in Figure S9, with the increase of deposition time, the heavily defective membrane $(4 \mathrm{~h})$ first reached a full but loosely-packed coverage $(8 \mathrm{~h})$, and then became intact and densely packed (16 to $32 \mathrm{~h}$ ). The thickness of the PB membrane reached $800 \mathrm{~nm}$ with a deposition time of $32 \mathrm{~h}$.
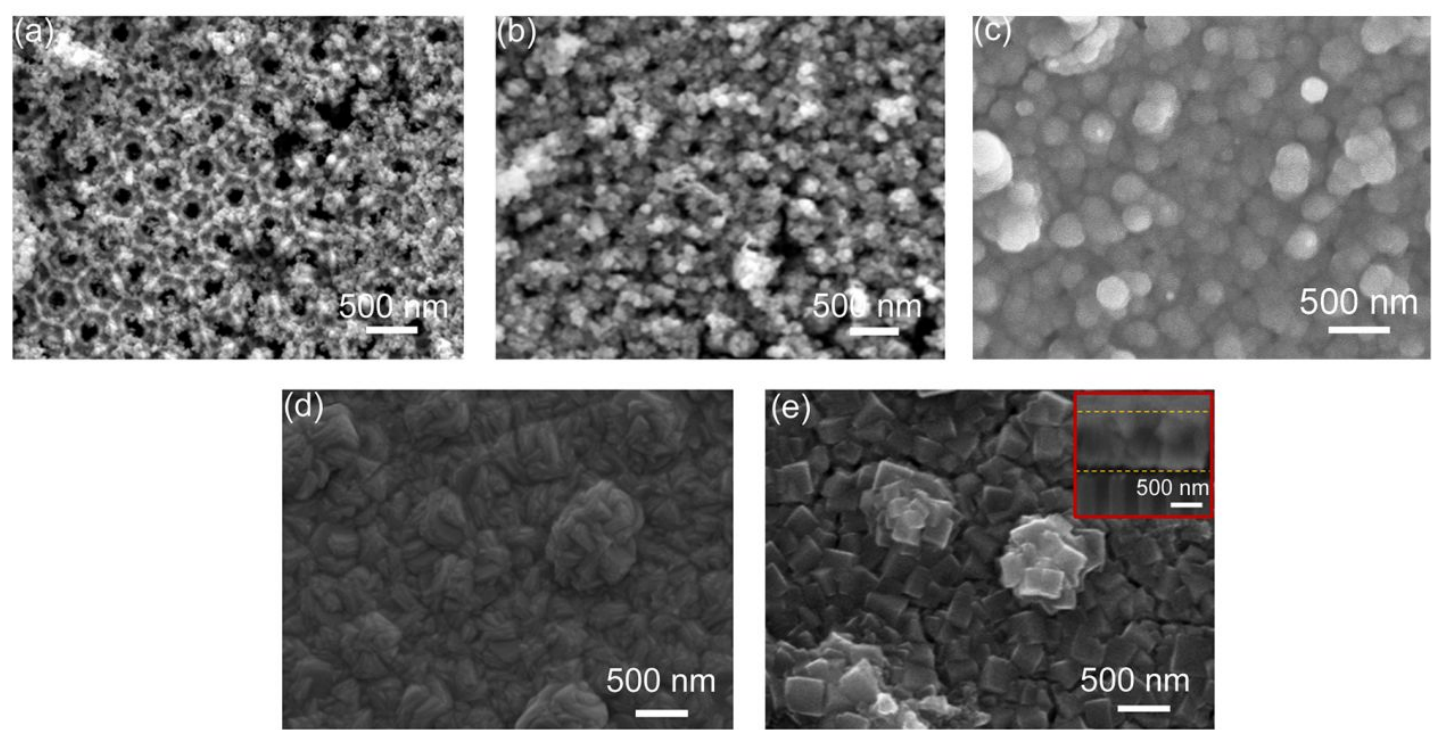

Figure S9. SEM images of the PB membranes fabricated with different deposition times: (a) $4 \mathrm{~h}$; (b) $8 \mathrm{~h}$; (c) $16 \mathrm{~h}$; (d) $24 \mathrm{~h}$; (e) $32 \mathrm{~h}$. Insert in (e) shows the cross-section. 
S10. Permeation rate of $\mathrm{K}^{+}$across ETISM with different deposition times

As shown in Figure S10, the permeation rate of $\mathrm{K}^{+}$sharply decreased with the growth of PB membrane.

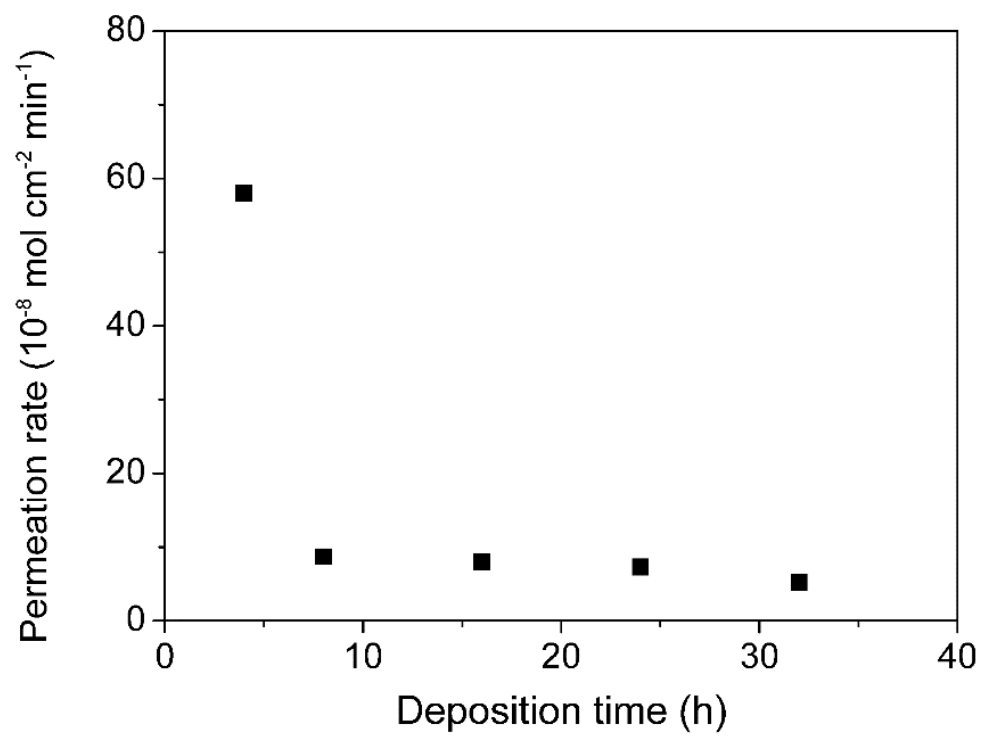

Figure S10. Permeation rate of $\mathrm{K}^{+}$across ETISM with different deposition times. 